\title{
Cartografias periféricas: aprendizagem de desenvolvimento de software em favelas cariocas
}

Irapoan Nogueira Filho

\begin{abstract}
Resumo
Este artigo constitui o relato da experiência de intervenção, realizada a partir da solicitação de uma ação social na cidade do Rio de Janeiro: o "Vai na Web", programa feito por moradores e ex-moradores de favelas, e que visa ensinar desenvolvimento de software e colocar profissionalmente jovens de duas localidades: o Morro dos Prazeres e o Complexo do Alemão. A ação militar federal que ocorreu na cidade a partir de fevereiro de 2018 apresentou novos desafios para o programa. O método utilizado para a intervenção foi a cartografia esquizoanalítica. A demarcação conceitual utilizada para o início da intervenção foram os estudos em Politicas da Cognição, com o objetivo de compreender os movimentos cognitivos potentes já presentes para, a partir dos mesmos, tecer a ação. Obteve-se a construção de métodos pedagógicos que tivessem como princípio os territórios cognitivos das comunidades onde o projeto está inserido - o que resultou em um aumento do aproveitamento e da penetração no mercado dos egressos do programa. Conclui-se que, apesar da obtenção parcial de resultados satisfatórios no aproveitamento do programa, ainda se faz necessário criar ferramentas para lidar com este quadro em que políticas públicas infligem diretamente elou indiretamente na cognição.
\end{abstract}

Palavras-chave: cartografia; intervenção; desenvolvimento de software; favela.

\section{Peripheral cartography: software development learning in slums from Rio de Janeiro}

\begin{abstract}
This article is the report of the experience of an intervention, carried out from the request of a social action in the city of Rio de Janeiro: "VainaWeb", a program made by residents and former slum dwellers, aimed at teaching software development and putting young people professionally residents of two locations: the Morro dos Prazeres and the Complexo do Alemão. The federal military intervention that occurred in the city on February 2018 presented new challenges for the program. At the same time, it was noticed the absence of academic papers on the subject, in Psychology. The method sed for the intervention was Cartography, based on Schizoanalysis. The conceptual demarcation that was used for the beginning of the intervention were the studies in Cognition Policies, with the objective of understanding the powerful cognitive movements already present to make the action. The intervention resulted in the construction of pedagogical methods that had as a principle the cognitive territories of the communities where the project is inserted-which resulted in an increase in the use and market penetration of the graduates of the program. It is concluded that, despite the partial achievement of satisfactory results in the use of the program, it is still necessary to create tools to deal with this situation in which political phenomena inflict directly on cognition, collaborating with cognition in its disruptive power and inventive resistance.
\end{abstract}

Keywords: cartography; intervention; cognition; software development; shantytown.

\section{Apresentando o contexto da intervenção}

O presente trabalho constitui-se no registro de uma intervenção que tem por referencial metodológico a cartografia. ${ }^{1}$ Constitui o relato de atividades exercidas em uma intervenção ainda em andamento, utilizando o método supracitado. Tal intervenção foi tecida por um diálogo entre o Núcleo de Estudos em Cognição, Atividade e Gestão (NECAG), no Instituto Três Rios, da Universidade Federal Rural do Rio de Janeiro; e o Instituto Precisa Ser, no Rio de Janeiro. O Núcleo foi procurado pelo fato de o Instituto ter conhecimento de algumas de suas produções anteriores, com outras minorias - usuários de serviços de saúde mental e população rural (NOGUEIRA FILHO, 2016; NOGUEIRA FILHO; GOULART; SANZ, 2017). Esta procura consistiu na solicitação de uma intervenção.

Todavia, Antes de discorrer sobre a intervenção, faz-se necessário apresentar o campo que comparece como convocador da mesma.

\footnotetext{
^Endereço para correspondência: Universidade Federal Rural do Rio de Janeiro, Instituto Três Rios. Rua Marechal Deodoro, Centro - Três Rios, RJ - Brasil

CEP: 25802-220.E-mail: infilho@gmail.com

Os dados completos do autor encontram-se ao final do artigo. Ver mais adiante
}

O Instituto Precisa Ser é uma plataforma de ação coletiva em inovação social. Esse instituto possui, dentre suas ações, uma incubadora de projetos sociais, artísticos e laborais de moradores de favela; um programa de atuação com iniciativas sociais em favelas; e um programa de democratização de tecnologia, com o objetivo de formação de polos de tecnologia em favelas. Este último projeto constitui o Vai $\mathrm{Na}$ Web.

Percebendo as favelas como territórios potentes e cheios de vida, o Vai na Web tem como objetivo democratizar o acesso à tecnologia, promover a diversidade de gênero, raça/etnia, cultura e formar profissionais de excelência. Para cumprir este objetivo, propõe ensinar educação digital avançada em linguagens de programação sofisticadas e desejadas pelo mercado, além de habilidades socioemocionais (VAI NA WEB, 2017). Cabe apontar que mais de $90 \%$ dos instrutores do programa são oriundos ou moradores de regiões periféricas. Alguns, inclusive, moram nas localidades onde trabalham e tiveram a formação no próprio programa.

O Vai na Web está dividido em três módulos independentes e de crescente complexidade, e cada um corresponde a um âmbito de formação profissional. Cada 
módulo está organizado por meio de aulas expositivas, tarefas individuais (presenciais e virtuais) e tarefas em grupo (presenciais e virtuais). Conta-se, ainda, com aplicativos eletrônicos de diálogos coletivos (grupos de Whatsapp) sobre os conteúdos do módulo. Ainda, no fim do módulo, os discentes dividem-se em grupos para a realização de projetos e software para a comunidade, no campo de atuação do respectivo módulo. A avaliação dos projetos ocorre por meio de acompanhamento de sua realização, e não da avaliação de seu resultado final. À época da redação deste artigo eram realizadas, como são ainda hoje, festas de aniversários dos participantes, saídas coletivas para eventos culturais, além de os discentes e instrutores visitarem uns aos outros.

Uma das questões colocadas dentro dessa ação coletiva foi como aprimorar a eficácia, em termos de índice de aproveitamento, das ações, e construir plataformas para mensurar os mesmos índices. Em diálogo com um dos agentes nesta ação coletiva, que já conhecia trabalhos anteriores com outros tipos de populações minoritárias - usuários de serviço de saúde mental e campesinos (NOGUEIRA FILHO, 2012, 2016; NOGUEIRA FILHO; GOULART; SANSZ, 2017) - foi elaborado um acordo de cooperação técnico-científica entre o NECAG e o Instituto. A atuação da equipe pesquisadora procura, com base na demanda inicial, estabelecer novos caminhos para a colaboração com o projeto. E, ao mesmo tempo, torna-se possível a criação de conhecimento metodológico-teórico.

Utilizando a cartografia como método de intervenção, não se busca retratar fenômenos e realizar ações sobre o quadro estabelecido, mas acompanhar os processos existentes e colaborar para aqueles que favorecem a produção de saúde (PASSOS; BARROS, 2003). Ou seja, colaborar com tentativas concretas para expandir as capacidades do coletivo (educandos e instrutores) contra a instabilidade inerente à vida. Assim, o alvo da intervenção será abordado partindo de suas capacidades, e não apenas o que é de caráter "sintomático" ou frágil.

Desta maneira, se pretendeu compreender o programa em seu processamento, os movimentos de produção de bons encontros com seu público-alvo, bem como as questões que se apresentassem naturalizadas ou entravadas. Sendo a cartografia de base Esquizoanalítica (DELEUZE; GUATTARI, 1995a, 1995b, 1997; PASSOS; KASTRUP; ESCÓSSIA, 2010), cabe apreender o alvo da intervenção a partir da perspectiva de multiplicidade (DELEUZE; GUATTARI, 1995a).

"[É] somente quando o múltiplo é efetivamente tratado como substantivo, multiplicidade, que ele não tem mais nenhuma relação com o uno como sujeito ou como objeto" (DELEUZE; GUATTARI, 1995, p. 16). Compreender o mundo a partir do conceito de multiplicidade é compreender que existem grandezas e dimensões do fenômeno apreendido pela análise que não podem crescer sem que mude sua natureza. Por exemplo, a expansão dos territórios cognitivos dos discentes do Vai na Web só pode ser entendida a partir de uma transformação desses territórios cognitivos. Assim, é necessário compreender o programa em seu constante processamento e em constan- te coprodução de si, no relacionar-se com os territórios onde estão inseridos, partindo das relações tecidas entre os discentes e o programa para compreender que territórios cognitivos são forjados a partir destas relações.

Uma vez explicitado o campo de composição das territorialidades, faz-se necessário explicitar as ferramentas teórico-metodológicas adotadas. Após, apresentam-se as mobilizações-ações feitas no campo, dificuldades encontradas, problematizações e soluções postas em jogo. Ao cabo, apresentam-se as pistas encontradas no processo.

\section{Cartografia como escolha metodológica}

Ao utilizar a proposta da Esquizoanálise, a cartografia constitui um método de pesquisa-intervenção que pressupõe a inseparabilidade entre fazer e conhecer (PASSOS; KASTRUP; ESCÓSSIA, 2010). Intervir é, portanto, produzir conhecimento. E esta intervenção acontece em um plano de afetação recíproca, agenciando sujeito e objeto - que são produzidos, simultaneamente, pelo cartografar.

Isto porque a cartografia acontece não por meio de agenciamento. Um agenciamento situa-se entre fluxos heterogêneos, sendo superfície de estratificação que os coloca em contato direto: não se trata de uma relação entre dois termos dados, mas o que vai constituir ambos, sujeito cognoscente e objeto cognoscível. Eles são as linhas e as velocidades que entram em relação, de modo a compor um e outro. Implica afecções e (pro)põe desterritorializações e territorializações. Suscitará linhas de fuga no sistema cognitivo.

$\mathrm{O}$ agenciamento possui duas faces. Uma é constituir-se em agenciamento maquínico de corpos - resultando em uma máquina que põe em relação imediata os fluxos cognitivos, afetivos e técnicos que dele participam. Entre sujeito e mundo há circulação de afecções e efeitos recíprocos em uma zona de osmose, de indiscernibilidade e produção de diferença. A outra face é a de agenciamento coletivo: o instrumento não se define como entidade puramente técnica. Por exemplo, ao desenvolver um website, os discentes do Vai na Web não interagem somente com o hardware e o software (maquínico), mas também com o cliente e com os futuros usuários do website, devendo coordenar a aparência do mesmo, bem como planejar sua navegação de modo que o site seja acessível a um número estipulado de pessoas ao mesmo tempo.

Desta maneira, a intervenção na cartografia não se dá em um "campo" preestabelecido (PASSOS; BARROS, 2010). Tanto o pesquisador quanto o território pesquisado são criados reciprocamente no ato de pesquisar, constituindo um território sempre móvel, provisório, inacabado, em constante produzir.

Entendo que o conceito de território constitui um ambiente de vida que só existe para aquele que o habita, sendo conjunto de interações entre vivente e meio. É um domínio cognitivo, afetivo e estético do sujeito (DELEUZE; GUATTARI, 1995a). É, portanto, construído no rastro da interação entre pesquisador e população pesquisada, sendo produção coletiva. Logo, o território produzido no rastro da cartografia constitui um plano comum de produção de sentido. É desta maneira que o ato de 
conhecer coincide com o ato de intervir. A cognição não é, portanto, vista como apenas um conjunto de normas de resolução de problemas de construção de software... mas também modos de empreender seu uso, ensinar futuros participantes, transformar problemas da vida em problemas de software, e modificar.

\subsection{Conhecer, demarcar e produzir territórios: encontrando limites na produção da Psicologia sobre a periferia}

Costa e Nascimento (2005) descrevem, ainda, a existência de estudos sobre aspectos de políticas públicas, imaginário popular associado a um quadro conceitual preconceituoso. Conforme se percebe no levantamento dos autores, a favela é pesquisada no sentido de margem/marginal, habitação irregular, bem como os perigos que nela existem.

Especificamente, selecionando para fim de entendimento de "estado da arte" de estudos de Psicologia e Favela, realizaram-se buscas no Google Acadêmico, no Portal de Periódicos Capes e SciELO. Os documentos selecionados foram apenas os artigos, modalidade de comunicação científica que costumam apresentar os resultados de pesquisa mais recentes. O período abrangido pela busca foi o compreendido entre 2015 e 2018, período no qual se buscou caracterizar a produção recente no campo.

Os verbetes foram selecionados devido ao fato de este projeto ser realizado por moradores de favela para moradores de favela. A favela é, desta maneira, cenário e palco no qual ocorrem as ações do Vai na Web. Desejou-se, com esta busca, mapear como a academia compreende a favela para saber quais contribuições ela dá para compreender este cenário que traça o campo de interações possíveis de onde ocorre o programa.

A pesquisa em cada uma das referidas bases foi norteada pela associação da expressão "psicologia" com as palavras "favela", "comunidade" e "periferia". Assim, a obtenção dos artigos ocorreu por meio do pareamento entre psicologia, e cada uma dessas palavras indicativas de modos de se referenciar as comunidades de classes trabalhadoras lidas como marginais pelo setor público.

Nos sites de busca Google Acadêmico, bem como no Portal de Periódicos Eletrônicos de Psicologia (PePSIC) e no SciELO, predominam-se ainda temáticas de violência, periculosidade e retrato da favela como "comunidade carente". E uma predominância de trabalhos constituindo intervenção no campo da Psicologia Comunitária. Há, também na Psicologia, uma escassez de trabalhos que abordem a favela a partir do que há de potente, de produção de vida, para além do signo da alteridade, do estigma de "comunidade carente" - e da leitura de "área violenta".

Lê-se a favela a partir da perspectiva do asfalto. Faz-se necessário mobilizar ferramentas teórico-metodológicas que consigam ler a favela - bem como os fenômenos que nela ocorrem - a partir de sua óptica própria. $\mathrm{O}$ método da cartografia parece interessante nesta tarefa, por estar interessado em acompanhar os processos existentes, em vez de retratar e catalogar. Com este método, nesta intervenção,

Fractal, Rev. Psicol., v. 31 - n. esp., p. 173-178, set. 2019 buscou-se utilizar os estudos em políticas da cognição, utilizados nesta intervenção como ferramentas de análise e ponto de partida para o percurso desta cartografia.

\subsection{Cartografando políticas cognitivas}

Esta expressão tem sido encontrada na literatura científica para sinalizar uma distinção entre um modelo de cognição enquanto representação de um mundo preexistente, e um modelo de cognição enquanto processo de invenção de si e do mundo (KASTRUP, TEDESCO; PASSOS, 2008). Modelos estes que, para além de distintos modelos teóricos, são também dois modos distintos de existir no mundo, de estabelecer relação consigo próprio, e com a própria atividade de conhecer. A Política de Cognição abrange, portanto, um conjunto de posturas em relação ao mundo e a si mesmo, bem como ao conhecimento e ao processo de conhecer - ocasionando, portanto, práticas que têm efeito concreto no cotidiano.

No que tange às práticas existentes em favelas, a leitura científica encontrada tem partido do princípio de que há déficit, algo a menos, algo deficitário em relação à não-favela. Práticas que pensam a cognição enquanto idêntica a si, e que tomam uma leitura de déficit para todo e qualquer exercício cognitivo que ocorra de maneira distinta daquele do não-favela. E, faz-se necessário apontar, o próprio discurso sobre "A" favela é produtor de uma falsa homogeneidade, apagando as singularidades pertencentes a cada microcultura (cada favela é UMA favela), e absorvendo esse simulacro falsamente homogêneo sob o símbolo do déficit: "A" favela vira sinônimo de "comunidade carente", carências essas definidas a partir da perspectiva da não-favela - que por si só é repleta de idiossincrasias e dessemelhanças dentro de si.

Torna-se possível, então, uma percepção sobre uma produção de determinadas políticas cognitivas sobre a favela. A partir da expressão políticas de cognição como ferramenta conceitual de análise, tomando a cartografia como ferramenta metodológica de intervenção, podem se encontrar algumas perguntas por onde começar:

a) Que práticas de ensino-intervenção estão envolvidas?

b) Qual percepção e relacionamento o público-alvo dessas práticas têm com essas práticas?

c) Em que medidas há descompasso entre o desejado e o presente, e quais os impasses enfrentados no momento?

d) E, sobretudo, como auxiliar os movimentos de construção de potencialidades cognitivas ali presentes?

\section{Relatando uma cartografia entre políticas cognitivas e políticas de segurança}

Cabe, nesta seção, apresentar um relato dos caminhos adotados na intervenção até agora conduzida. Em primeiro lugar, são apresentados os resultados obtidos dos encontros dialógicos iniciais. Após, serão apresentados os resultados provisórios obtidos. Cabe agora desenvolver o relato desta experiência, apontando a existência no início da intervenção, da presença de uma equipe composta por 
dois instrutores, um professor, uma coordenadora pedagógica, um assistente social e dois analistas de relações institucionais. A equipe se dividia entre atividades no Morro dos Prazeres e no Complexo do Alemão. Alguns realizavam atividades em ambas as comunidades. $\mathrm{O}$ número total de alunos do curso, em seus diferentes módulos, era de 113, com idade a partir de14 anos.

Uma demanda surge nos primeiros dias, por parte dos profissionais: de que eu seria o especialista em "escutar o sofrimento dos alunos", expectativa esta acompanhada de outra: a de que eu seria o especialista que fizesse todos se sentirem bem. Foi realizado um encontro de 4 horas, apresentando à equipe a conversa inicial que deu origem à solicitação de intervenção bem como a sua composição.

Este encontro foi mais do que uma reunião formal: fazia-se necessário articular novos agenciamentos, havia um hábito de concentração das decisões nos quadros de gestão do programa - quadro este que não era questionado pela gestão, quando solicitou a intervenção. Outro agenciamento foi necessário tecer, para a compreensão e resolução daquilo que era apontado como "não-aproveitamento discente": um diálogo com toda a equipe, por meio do qual a fala dos instrutores do programa não estivesse subordinada e obediente aos quadros de gerência. Cabe aqui apontar um fato interessante: o então presidente do instituto era não apenas oriundo de favela, mas também militar.

Assim, os resultados produzidos pela conversa inicial foram submetidos à apreciação da equipe, que ainda colaborou em tornar qualitativamente mais expressivos os motivos de solicitação de intervenção:

- Lidar com questões ligadas à segurança pública que interferem diretamente no ensino (desde o exercício das atividades até a possibilidade de translado ao local de ensino);

- O calor nas instalações colaborava para a qualidade do desempenho;

- Falta de planejamento de tempo dos discentes implicando mau aproveitamento;

- Alguns discentes com bom rendimento, mas que não acreditavam em uma empregabilidade futura;

- Presença de uma correlação entre evasão e ser "arrimo de família";

- Relatos recorrentes de alunos com autoimagem de "favelado" utilizada pela mídia, acompanhados de discursos sobre "não ser para mim este trabalho";

- Falta de clareza de delimitação de projeto de egresso do Vai na Web;

- No mesmo projeto, há uma miscelânea de aulas díspares ministradas uma vez por semana, mescladas sob o título de "aulas de cidadania".

- As deliberações coletivas se tornaram um instrumento cotidiano e permanente de desenho e apreciação e destes desafios que estavam presentes no programa. Passaram, portanto a fazer parte do próprio programa. Não se tratava mais tão-somente de uma escola gratuita de desenvolvimento de software. Acentuou-se seu caráter de produção coletiva, em que os discentes têm, inclusive, um papel protagonista. Tornou-se possível propor novos caminhos, resultando em:

- Tratamento de condições de temperatura (ar-condicionado) nos ambientes das classes;

- Elaboração de um perfil de egresso, no que tange ao projeto Vai na Web;

- Divulgação posterior deste mesmo perfil de egresso nas comunidades interna e externa;

- Planejamento de um projeto pedagógico para aquilo que tem se chamado de "aulas de cidadania", transformadas em "habilidades socioemocionais"; 2

- Aplicação de um "Treinamento de Integração"3 para os alunos e familiares, que consistia apenas em uma recepção e na apresentação da cultura, da história e da proposta do projeto;

- Criação e formalização, pelo interventor, de um protocolo de Processo Seletivo Inclusivo para participação - em que se verificava com o candidato, a existência de condições para o exercício no curso. Em caso negativo, realizar-se-ia um acompanhamento com o candidato, para auxiliá-lo na obtenção dessas condições até a próxima seleção;

- Proposição de um acompanhamento individual, atendendo às singularidades de cada estudante;

- Criação de dois polos de desenvolvimento de software nas respectivas comunidades, nos quais os(as) desenvolvedores(as) são oriundos(as) do programa;

- Foram também executados treinamentos didáticos para os instrutores, melhorando, inclusive, a sua avaliação - não apenas os estudantes eram avaliados, mas todos os participantes.

Quando se transformam as "aulas de cidadania" em aulas de "habilidades socioemocionais", ${ }^{4}$ tem-se o intuito de tecer outros caminhos para a aprendizagem e colocá-la como processo psicossocial e coletivo (ABED, 2016). Ainda, outra intervenção foi feita: tais aulas de habilidades socioemocionais começariam por uma nova aula: "Introdução à História da Favela".

A proposição de iniciar com Introdução à "História da Favela" teve o intuito de resgatar as narrativas presentes no território a partir delas próprias, e não da lógica do "asfalto". E, partindo da aula e dos estudos solicitados, possibilitar aos discentes do projeto a construção de novas narrativas e subjetividades, diferentes daquelas que lhes são atribuídas pela sociedade "asfaltocêntrica", eliciando, por meio de ruptura nas subjetividades, a potência no pensar e agir presentes nos territórios.

As falas e os trabalhos produzidos pelos discentes possibilitaram a emergência de diálogos e percepções de si e do território que não são permeados por uma visão de si mesmos como o outro. "O favelado e a favelada" da mídia (aqui, no sentido pejorativo) são substituídos pe-

${ }^{2}$ Apesar dos posicionamentos da equipe interventora sobre este termo, ele foi preferido pela maioria dos participantes do projeto.

${ }^{3}$ Idem.

${ }^{4}$ Cabe apontar que a equipe de intervenção se opôs à tal nomenclatura. Todavia, o coletivo do programa recusou e desejou colocar esta expressão. 
los favelados e faveladas da favela, potentes, disruptivos. Dentro destes diálogos são construídas novas percepções acerca das possibilidades do próprio território, que passou a ser entendido como campo passível de ser explorado e fortalecido. Um novo agenciamento-favela, favelas que passam a ser ocupadas de maneira potente.

Tais medidas possibilitaram um aumento de aproveitamento no curso (em 2017, concluíram 56 dos discentes, sendo 10 estudantes imediatamente incorporados no mercado). O desenvolvimento parecia promissor. Foram alcançados, no decorrer desse um ano de pesquisa-intervenção, resultados como:

- Surgimento de dois polos de tecnologia no Morro dos Prazeres e no Complexo do Alemão (Estúdios Vai na Web);

- Realização de contrato dos Estúdios de tecnologia com a Universidade de Stanford (EUA) para prestação de serviços, entre outros contratos;

Realização de interlocução com outros campos de tecnologia voltados para causas sociais.

Todavia, a partir de março de 2018, foi possível notar outro espectro de problemas adicionado ao projeto. Devido ao decreto de intervenção federal no Rio de Janeiro (Decreto 9.288, de 16 de fevereiro de 2018 [BRASIL, 2018]), não raro ocorrem incursões militares no Complexo do Alemão paralisando e até inviabilizando as atividades do programa por mais de 30 dias. A incidência de queda do sinal de internet e luz aumentou, também paralisando as atividades. A frequência de conflitos no Morro dos Prazeres também se acentuou. Alguns candidatos foram proibidos pelos responsáveis de se inscreverem e comparecerem ao programa por temerem incidentes de segurança. Soma-se a isso o aumento expressivo do desemprego (BRASIL, 2017). O índice de matriculados no programa caiu para 84 , e o de concluintes diminuiu para 28 (dados do programa, colhidos em outubro de 2018). Ainda, o número de concluintes imediatamente absorvidos pelo mercado de trabalho subiu para 13. Percebe-se, assim, que o vetor segurança pública atuou de maneira acentuada no sentido de reforçar barreiras de exclusão. Visa-se no momento à elaboração de estratégias para a retenção dos participantes.

\section{Considerações finais}

Os efeitos da intervenção militar dentro destas comunidades infligem diretamente no cotidiano e nas territorialidades: a intervenção surgiu e seus feitos sobrepuseram-se a outros movimentos. Nota-se que foi interessante utilizar ferramentas da psicologia que não se resumem à Psicologia Comunitária para ação, evocando ao saber psi que em comunidades periféricas há mais que periculosidade, crime e outros estereótipos.

Foi profícuo pensar a favela para além de seu enquadramento a partir do asfalto, e colaborar para a emergência, no local de intervenção, de outros modos de pensar-conhecer-fazer que não centrados na lógica do asfalto. Os avanços conseguidos a partir da utilização conceitual de Políticas da Cognição nos mostram como os saberes psi ainda estão presos a uma lógica de pensamento centrada na classe média.

Todavia, agir na e com a favela faz com que esses mesmos saberes sejam confrontados com o caráter concreto, dificultado e cotidiano da experiência humana. Não se torna interessante pensar em simplificações, torna-se necessário agir no concreto: procurar saber suas horas dormidas e o que tem na geladeira. Em um paradigma de retorno da fome, de aumento de desemprego e de formas outras de habitar-existir na cidade, faz-se necessário atentar para uma psicologia viva, que "pega ônibus, olha as crianças com panela no fogo e roupa no varal"... uma psicologia que se desenvolva, em vez de adorar normas descobertas/ feitas no século passado. Intervir sobre desenvolvimento de software nos atenta para a necessidade de desenvolver nossas ferramentas de intervir-conhecer (n)o mundo.

\section{Informações sobre o autor:}

\section{Irapoan Nogueira Filho \\ (iD) https://orcid.org/0000-0002-7180-3439 \\ (9) http://lattes.cnpq.br/8156912484343709}

Psicólogo, possui doutorado em Psicologia Social Pela Universidade do Estado do Rio de Janeiro, tendo concluído seu mestrado pela mesma universidade. Atualmente é Professor Adjunto da Universidade Federal Rural do Rio de Janeiro. Atua na área da Psicologia, com ênfase em Psicologia Social do Trabalho em interface com a Psicologia da Cognição. Seu trabalho, no âmbito de pesquisa-intervenção em populações minoritárias, aborda principalmente os seguintes temas: Cognição Inventiva, Políticas de Cognição, Saúde Mental, Cognição no Trabalho, Subjetividade.

\section{Como citar este artigo:}

\section{ABNT}

NOGUEIRA FILHO, Irapoan. Cartografias periféricas: aprendizagem de desenvolvimento de software em favelas cariocas. Fractal: Revista de Psicologia - Dossiê Psicologia e epistemologias contra-hegemônicas, Niterói, v. 31, n. esp., p. 173-178, set. 2019. https://doi.org/10.22409/1984-0292/v31i_esp/28999

\section{APA}

Nogueira Filho, I. (2019, set.). Cartografias periféricas: aprendizagem de desenvolvimento de software em favelas cariocas. Fractal: Revista de Psicologia - Dossiê Psicologia e epistemologias contra-hegemônicas, 31(esp.), 173-178. doi: https:// doi.org/10.22409/1984-0292/v31i_esp/28999

\section{Referências}

ABED, Anita Lilian Zuppo. O desenvolvimento das habilidades socioemocionais como caminho para a aprendizagem e o sucesso escolar de alunos da educação básica. Construção Psicopedagógica, São Paulo, v. 24, n. 25, 2016. 8-27. Disponível em: http://pepsic.bvsalud.org/scielo. php?script=sci_arttext\&pid=S1415-69542016000100002\&lng =pt\&nrm=iso. Acesso em: 15 out. 2018.

BRASIL. Instituto Brasileiro de Geografia e Estatística. Pesquisa Nacional por Amostra de Domicílios Contínua (PNAD). 2017. Disponível em: https://ww2.ibge.gov.br/home/ estatistica/pesquisas/calendario_2017.php. Acesso em: 10 out. 2017. 
BRASIL. Presidência da República. Casa Civil. Subchefia para Assuntos Jurídicos. Decreto $n^{\circ}$ 9.288, de 16 de fevereiro de 2018. Decreta intervenção federal no Estado do Rio de Janeiro com o objetivo de pôr termo ao grave comprometimento da ordem pública. 2018. Disponível em: http://www.planalto.gov. br/ccivil_03/_ato2015-2018/2018/decreto/D9288.htm. Acesso em: 22 jul. 2018 .

COSTA, Valéria Grace; NASCIMENTO, José Antônio Sena do. O conceito de favelas e assemelhados sob o olhar do IBGE, das prefeituras do Brasil e da ONU. In: ENCONTRO DE GEÓGRAFOS DA AMÉRICA LATINA, 10, 2005, São Paulo. Anais... São Paulo: Universidade de São Paulo, 2005. Disponível em: http://www.observatoriogeograficoamericalatina.org.mx/ egal10/Geografiasocioeconomica/Geografiadelapoblacion/14 . pdf. Acesso em: 12 jul. 2018.

DELEUZE, Gilles; GUATTARI, Félix. Mil platôs: capitalismo e esquizofrenia. Rio de Janeiro: Ed. 34, 1995a. v. 1.

DELEUZE, Gilles; GUATTARI, Félix. Mil platôs: capitalismo e esquizofrenia. Rio de Janeiro: Ed. 34, 1995b. v. 2.

DELEUZE, Gilles; GUATTARI, Félix. Mil platôs: capitalismo e esquizofrenia. Rio de Janeiro: Ed. 34, 1997. v. 4.

KASTRUP, Virgínia; TEDESCO, Silvia; PASSOS, Eduardo. Introdução. In: . Politicas da Cognição. Porto Alegre: Sulina, 2008. p. 9-17.

NOGUEIRA FILHO, Irapoan. Inventividade, trabalho $e$ transtornos mentais graves: sobre interferências recíprocas entre cognição e atividade. 2012. Tese (Doutorado em Psicologia Social)-Instituto de Psicologia. Universidade do Estado do Rio de Janeiro, Rio de Janeiro, 2012.

NOGUEIRA FILHO, Irapoan. El trabajo en la panadería y la salud mental: informe de una experiencia de intervención esquizoanalítica en una situación laboral. In: TRIMBOLI, Alberto. et al. (Org.). Los limites de la clínica. Ciudad Autónoma de Buenos Aires: AASM, 2016. p. 71-73.

NOGUEIRA FILHO, Irapoan; GOULART, João Pedro; SANZ, Jose Guido. Relações saúde e trabalho rural, em uma região agrícola do Estado do Rio de Janeiro: uma análise a partir do ponto de vista da atividade. Relatório de Pesquisa. Paty do Alferes, 2017.

PASSOS, Eduardo; BARROS, Regina Benevides de. Complexidade, transdisciplinaridade e produção de subjetividade. In: FONSECA, Tânia Mara Galli; KIRST, Patrícia Gomes. Cartografias e Devires: a construção do presente. Porto Alegre: UFRGS, 2003. p. 81-89.

PASSOS, Eduardo; BARROS, Regina Benevides de. A cartografia como método de pesquisa-intervenção. In: PASSOS, Eduardo; KASTRUP, Virgínia; ESCÓSSIA, Liliana da (Org.). Pistas do método da cartografia. Porto Alegre: Sulina, 2010. p. 17-31.

PASSOS, Eduardo; KASTRUP, Virgínia; ESCÓSSIA, Liliana da. Pistas do método da cartografia. Porto Alegre: Sulina, 2010.

VAI NA WEB. Diversidade, equidade e inclusão. 2017. Disponível em: https://www.vainaweb.com.br/socialEdTech. html. Acesso em: 1 set. 2018. 